\title{
Treatment of an aggressive aneurysmal bone cyst with percutaneous injection of polidocanol: a case report
}

Otte Brosjö ${ }^{1,2}$ and Panagiotis Tsagozis ${ }^{1,2^{*}}$

\begin{abstract}
Introduction: Aneurysmal bone cysts are benign tumours that usually present in childhood. Aggressive forms have been described, which are often treated with surgery that entails major resection and reconstruction. Polidocanol sclerotherapy has recently been reported to have excellent results and promises to replace operative treatments, but its efficacy in the case of aggressive aneurysmal bone cysts has not been documented.
\end{abstract}

Case presentation: An 18-year-old woman from Sweden presented with pain in her shoulder and a rapidly progressing cystic bone lesion. The differential diagnosis was a rare, aggressive form of aneurysmal bone cyst or a sarcoma of the proximal humerus. She was successfully treated using sequential percutaneous injections of polidocanol after exclusion of malignancy.

Conclusions: Management of aggressive aneurysmal bone cysts has thus far relied on open surgery. We propose that non-operative treatment with polidocanol is efficient even in the aggressive form of the aneurysmal bone cyst.

Keywords: Aggressive aneurysmal bone cyst, Polidocanol, Sclerotherapy

\section{Introduction}

Aneurysmal bone cysts (ABCs) demonstrate a spectrum of clinical presentations, from the latent to the active form and finally the rare aggressive variant [1]. The latter is sometimes extremely difficult to differentiate from telangiectatic osteosarcoma. A variety of treatments is available for $\mathrm{ABCs}$, ranging from curettage (with or without filling of the cavity with polymethylmethacrylate) or autologous en block excisions with reconstruction of the skeletal defect with autograft or allograft, cryosurgery, selective embolization of the feeding arteries or radiation [1-4]. Most authors have relied on a more radical resection and subsequent reconstruction of the skeletal defect in order to treat aggressive $\mathrm{ABCs}$ [5-8]. Healing has also been achieved by selective arterial embolization [9] or radiotherapy, combined or not with cryosurgery $[1,10]$.

Polidocanol sclerotherapy is a safe and effective treatment method $[11,12]$ that has gained popularity among

\footnotetext{
* Correspondence: tsagozis@gmail.com

'Section of Orthopaedics, Department of Molecular Medicine and Surgery, Karolinska Institute, Stockholm S-17176, Sweden

${ }^{2}$ Department of Orthopaedics, Karolinska University Hospital, Stockholm
} S-17176, Sweden

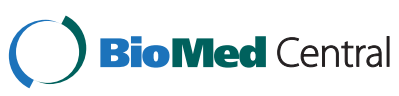

(c) 2014 Brosjö and Tsagozis; licensee BioMed Central. This is an Open Access article distributed under the terms of the Creative Commons Attribution License (http://creativecommons.org/licenses/by/4.0), which permits unrestricted use, distribution, and reproduction in any medium, provided the original work is properly credited. The Creative Commons Public Domain Dedication waiver (http://creativecommons.org/publicdomain/zero/1.0/) applies to the data made available in this article, unless otherwise stated. orthopaedic surgeons, but its applicability in the management of aggressive $\mathrm{ABCs}$ has not been reported. We report for the first time in the medical literature the successful non-operative treatment of an aggressive $\mathrm{ABC}$ using polidocanol sclerotherapy.

\section{Case presentation}

An 18-year-old woman from Sweden was admitted to our institution due to a painful mass in her left shoulder, discovered 2 months ago, and impairment in range-ofmotion (ROM). An ultrasound examination by the admitting primary care physician revealed a vascularized tumour. During physical examination, a palpable mass was present in close proximity to her deltoid muscle. A plain X-ray examination of her left humerus showed an osteolytic lesion (Figure 1a) and magnetic resonance imaging (MRI) revealed a $5.5 \mathrm{~cm}$ tumour which had a discrete soft tissue component (Figure 1b). Fine needle aspiration biopsy was inconclusive, most suggestive of myositis ossificans. Overall, telangiectatic osteosarcoma could not be excluded, a fact that led us to an open biopsy. The pathology report verified the diagnosis of $A B C$, without any evidence of malignancy. A repeat MRI, approximately 6 weeks after the

rach 

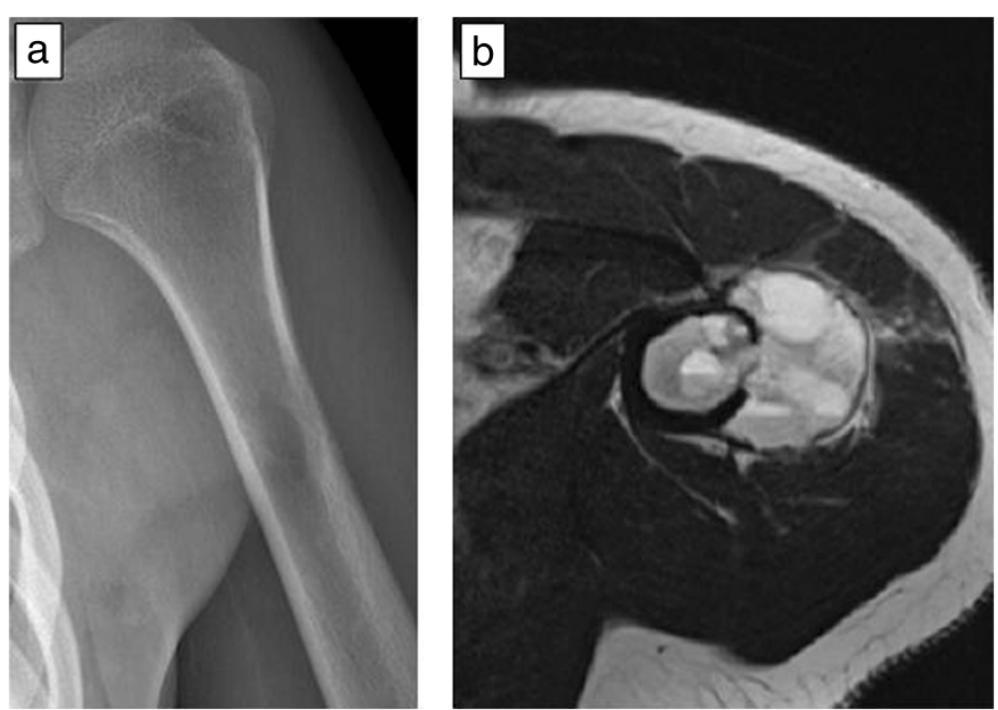

Figure 1 Plain radiograph of the patient showed an osteolytic lesion in the proximal humeral diaphysis (a), whereas magnetic resonance imaging revealed an expansile tumour that occupied the medullary cavity and gave rise to a soft tissue component (b).

first scan, however, showed a clear progression of both the intraosseous and the extraosseous components of the tumour, raising again the suspicion of sarcoma (Figure 2). This led to a second open biopsy, and the second pathology report was also consistent with an $\mathrm{ABC}$. The diagnosis of an unusually aggressive $A B C$ was set, and polidocanol sclerotherapy was initiated. She received six consecutive injections of $240 \mathrm{mg}$ of polidocanol under general anaesthesia and fluoroscopic guidance at approximately 3-week

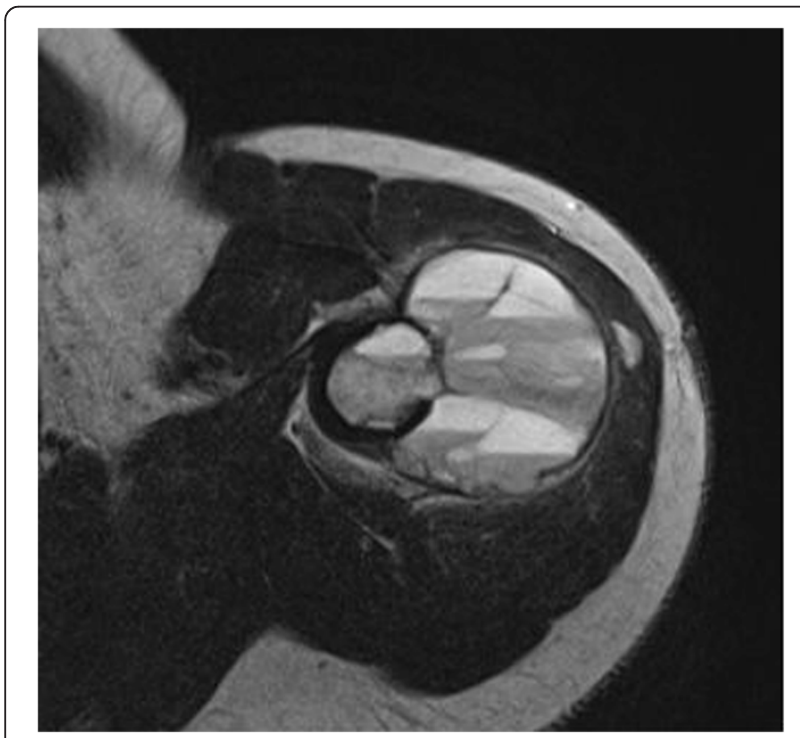

Figure 2 Repeat magnetic resonance imaging 6 weeks after the initial one, showing considerable growth of both the intraosseous as well as the soft tissue component of the aneurysmal bone cyst (approximately $30 \%$ and $300 \%$ respectively). time intervals (Figure 3a), until symptoms subsided and convincing radiological findings of healing of the lesion were observed. She had no symptoms at follow-up 3 months after the last injection, and her shoulder ROM was normalized. She remains symptom-free 1.5 years after the last injection, and there is radiologic consolidation of the lesion (Figure 3b).

\section{Discussion}

ABCs demonstrate a spectrum of clinical presentations, from the latent to the active form and finally the rare aggressive variant. The latter is sometimes extremely difficult to differentiate from telangiectatic osteosarcoma, as our case also clearly demonstrates. Referral to dedicated sarcoma centres, where clinical findings, radiology, cytology and pathology are interpreted by a multidisciplinary team offer clear advantages as far as diagnosis and therapy are concerned.

The biological aggressiveness of the lesion should be taken into account when choosing therapy, the more indolent forms can be treated with minimally invasive approaches or even observed, because there is a potential of spontaneous regression. As intralesional excisions have been associated with higher recurrence rate than wide excision, most authors have relied on a more radical resection and subsequent reconstruction of the skeletal defect to treat aggressive $\mathrm{ABCs}$.

The presented case suggests that the non-invasive treatment with polidocanol is equally effective in aggressive $\mathrm{ABCs}$, is not accompanied by side effects and seems to compare favourably to surgery. Indeed, morbidity associated to radical surgery is not negligible, time to recovery is 


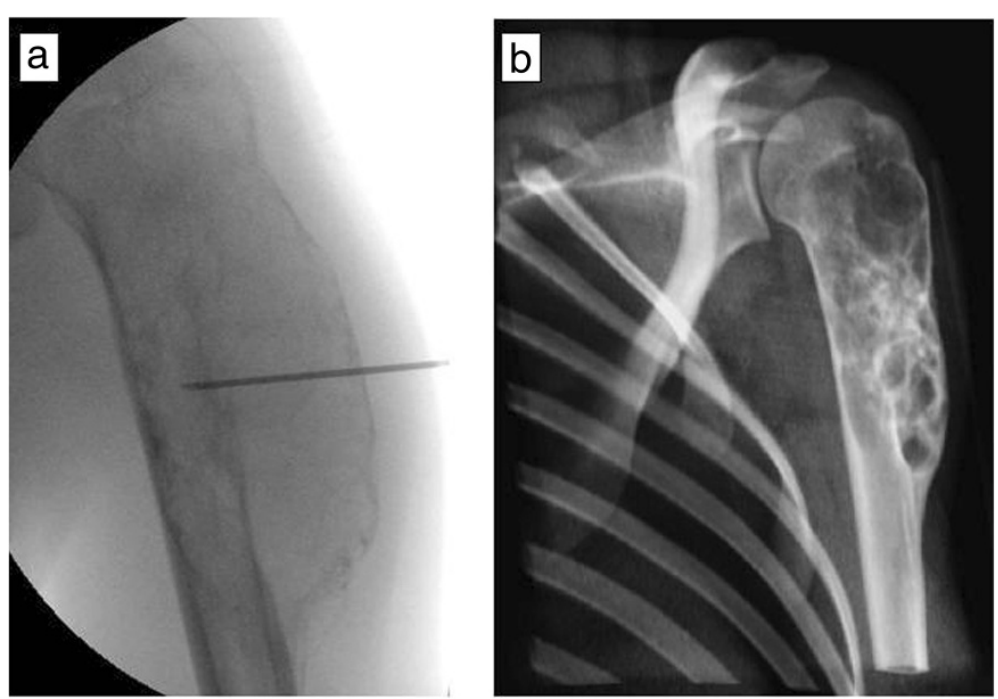

Figure 3 Fluoroscopy picture taken during the 5 th injection of polidocanol, showing proper placement of the needle and signs of sclerosis (a), and graphical reconstruction of a computed tomography scan of the proximal humerus, 18 months after the last treatment, showing consolidation of the lesion (b).

often prolonged, and failures of the reconstruction have been reported [5]. Other methods also have drawbacks: selective arterial embolization is technically demanding and not applicable to all cases as the lesions often lack defined feeding vessels and radiotherapy carries the risk for development of late sarcomas [10]. Polidocanol sclerotherapy is, according to our experience [13] and previously published data $[11,12]$, a simple and safe treatment that can be performed on an out-patient basis, with no serious side effects and with very high efficacy.

\section{Conclusions}

We suggest that polidocanol sclerotherapy be considered a treatment option for all $\mathrm{ABCs}$, including the aggressive lesions. This is an important finding because it shows the applicability of a simple non-operative method for the treatment of a disease, which previously entailed open surgery with a considerable risk for side effects.

\section{Consent}

Written informed consent was obtained from the patient for the publication of this case report and accompanying images. A copy of the written consent is available for review by the Editor-in-Chief of this journal.

\section{Abbreviations}

ABC: Aneurysmal bone cyst; MRI: Magnetic resonance imaging; ROM: Range-of-motion.

\section{Competing interests}

The authors declare that they have no competing interests.

\section{Authors' contributions}

OB treated the patient and conceived the report. PT collected data and wrote the manuscript. Both authors read and approved the final manuscript.

Received: 11 August 2014 Accepted: 25 November 2014

Published: 20 December 2014

\section{References}

1. Mendenhall WM, Zlotecki RA, Gibbs CP, Reith JD, Scarborough MT, Mendenhall NP: Aneurysmal bone cyst. Am J Clin Oncol 2006, 29(3):311-315.

2. Cottalorda J, Bourelle S: Current treatments of primary aneurysmal bone cysts. J Pediatr Orthop B 2006, 15(3):155-167.

3. Tomasik P, Spindel J, Miszczyk L, Chrobok A, Koczy B, Widuchowski J, Mrozek T, Matysiakiewicz J, Pilecki B: Treatment and differential diagnosis of aneurysmal bone cyst based on our own experience. Ortop Traumatol Rehabil 2009, 11(5):467-475.

4. Papagelopoulos PJ, Choudhury SN, Frassica FJ, Bond JR, Unni KK, Sim FH: Treatment of aneurysmal bone cysts of the pelvis and sacrum. J Bone Joint Surg Am 2001, 83-A(11):1674-1681.

5. Güven M, Demirel M, Ozler T, Başsorgun IC, Ipek S, Kara S: An aggressive aneurysmal bone cyst of the proximal humerus and related complications in a pediatric patient. Strategies Trauma Limb Reconstr 2012, 7(1):51-56.

6. Beslikas T, Chytas A, Christodoulou A, Gigis I, Christoforidis I: A giant scapular aneurysmal bone cyst in a child. Case Rep Orthop 2012, 2012:327023.

7. Randall RL, Nork SE, James PJ: Aggressive aneurysmal bone cyst of the proximal humerus. A case report. Clin Orthop Relat Res 2000, 370:212-218.

8. Cottalorda J, Kohler R, Lorge F: [Aggressive aneurysmal bone cyst of the humerus in a child]. Rev Chir Orthop Reparatrice Appar Mot 2004, 90(6):577-580.

9. Rossi G, Mavrogenis AF, Papagelopoulos PJ, Rimondi E, Ruggieri P: Successful treatment of aggressive aneurysmal bone cyst of the pelvis with serial embolization. Orthopedics 2012, 35(6):e963-e968.

10. Marcove RC, Sheth DS, Takemoto S, Healey JH: The treatment of aneurysmal bone cyst. Clin Orthop Relat Res 1995, 311:157-163.

11. Rastogi S, Varshney MK, Trikha V, Khan SA, Choudhury B, Safaya R: Treatment of aneurysmal bone cysts with percutaneous sclerotherapy using 
polidocanol. A review of 72 cases with long-term follow-up. J Bone Joint Surg (Br) 2006, 88(9):1212-1216.

12. Varshney MK, Rastogi S, Khan SA, Trikha V: Is sclerotherapy better than intralesional excision for treating aneurysmal bone cysts? Clin Orthop Relat Res 2010, 468(6):1649-1659.

13. Brosjö O, Pechon P, Hesla A, Tsagozis P, Bauer H: Sclerotherapy with polidocanol for treatment of aneurysmal bone cysts. Acta Orthop 2013, 84(5):502-505.

doi:10.1186/1752-1947-8-450

Cite this article as: Brosjö and Tsagozis: Treatment of an aggressive aneurysmal bone cyst with percutaneous injection of polidocanol: a case report. Journal of Medical Case Reports 2014 8:450.

\section{Submit your next manuscript to BioMed Central and take full advantage of:}

- Convenient online submission

- Thorough peer review

- No space constraints or color figure charges

- Immediate publication on acceptance

- Inclusion in PubMed, CAS, Scopus and Google Scholar

- Research which is freely available for redistribution 